\title{
DETERMINATION OF ST. GEORGE BASILICA TOWER HISTORICAL INCLINATION FROM CONTEMPORARY PHOTOGRAPH
}

\author{
Bronislav KOSKA \\ Czech Technical University in Prague, Faculty of Civil Engineering \\ Thákurova 7, Prague 6, Czech Republic \\ bronislav.koska@fsv.cvut.cz
}

Keywords: photogrammetry, bundle adjustment, datum problem, free network adjustment, covariant matrix

\begin{abstract}
A large amount of photographic material has been accumulated from the photography emerge in the nineteenth century. The most photographs record portraits, urbanistic complex, significant architecture and others important objects in the photography inception. Historical photographs recorded a huge amount of information, which can be use for various research activities. Photograph visual information is sufficient in many cases, but accurate geometrical information must be acquired from it in specific situations. It is the case of long-term stability monitoring of buildings in the Prague Castle area see [1]. For static analysis in the monitoring project, it is necessary to determine accurately specific geometrical parameter - mutual angle of St. George Basilica towers in the north-south direction before the reconstruction started in 1888. The angle standard deviation must be solved as well. The task demanded using of photogrammetric methods. Own implementation of general bundle adjustment had to be created to fulfill determination of reliable standard deviation of the angle, because standard photogrammetric software does not have all the necessary options.
\end{abstract}

\section{INTRODUCTION}

The paper deals with determination of St. George Basilica towers historical angle in the north-south direction from contemporary photographs. St. George Basilica has been founded in $920 \mathrm{AD}$ and it is the oldest surviving sacral building in Prague. Basilica 41 meters height towers have been added after fire in 1142. The basilica is situated in the Prague Castle area. Present inclination of the north tower is about 0.7 meter to the north direction on the top. St. George Basilica, alike others important building in the Prague Castle area, is under long term stability monitoring using standard surveying techniques (precise levelling, total stations) see [1]. The last significant basilica reconstruction started in 1888. Changing of the main nave construction was a part of the reconstruction and it could have affected the towers inclinations. Therefore it was decided to determine the north-south towers angle before the year of the reconstruction beginning. A historical photograph can be used for the purpose, if it is joined to the present photogrammetric project.

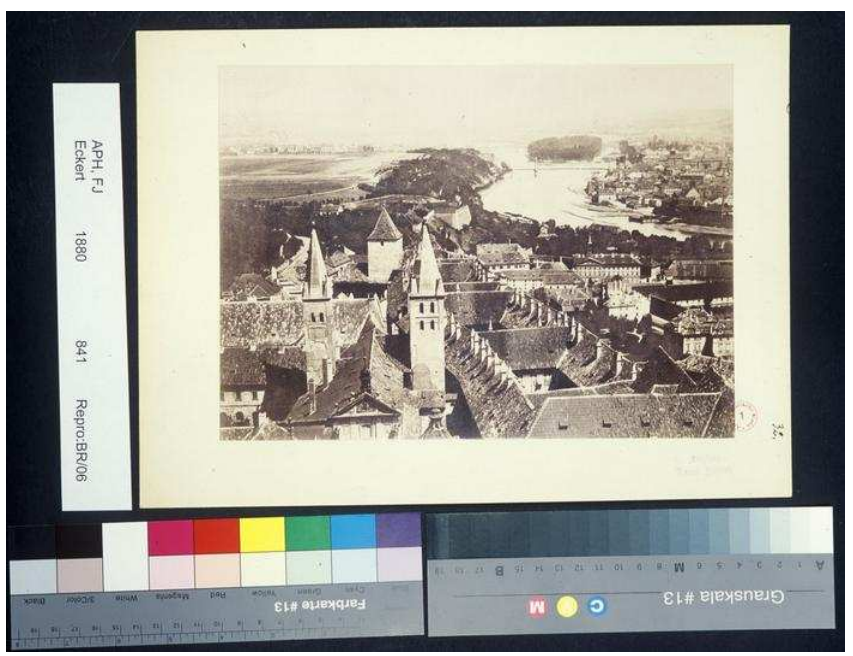

Figure 1: J. Eckert (1872) 


\section{HISTORICAL PHOTOGRAPHS}

Two usable photographs were found. Both of them were taken from the St. Vitus Cathedral tower, which was confirmed during project processing see Figure 8. It wasn't possible to get original negatives, but good quality historical positives were found in both cases. The first photograph was made by J. Eckert in 1872 (the photograph is further named Eckert). Its historical positive $(257 \times 185 \mathrm{~mm})$ is deposited in the Prague Castle archive. The archive also has medium format dispositive (see Figure 1) made by a professional photographer. The original glass plate isn't preserved. The medium format negative was scanned on the professional negative scanner Nikon Super CoolScan 8000ED using resolution 4000DPI. There exists a range of various transformations between original glass plate and final scan, which has influence on its accuracy (original glass plate - photograph - diapositive of photograph - scan). Standard deviations and residuals from processing on the photograph shows that all named transformations were realized in high quality manner with low influence on the image geometry. The second historical photograph was made by F. Fridrich in 1867 (see Figure 2, the photograph is further called Fridrich). It is a stereo-photo and its negative isn't preserved, but good historical positive is placed in the private archive of photographer P. Scheufler. The positive was scanned on high quality scanner.

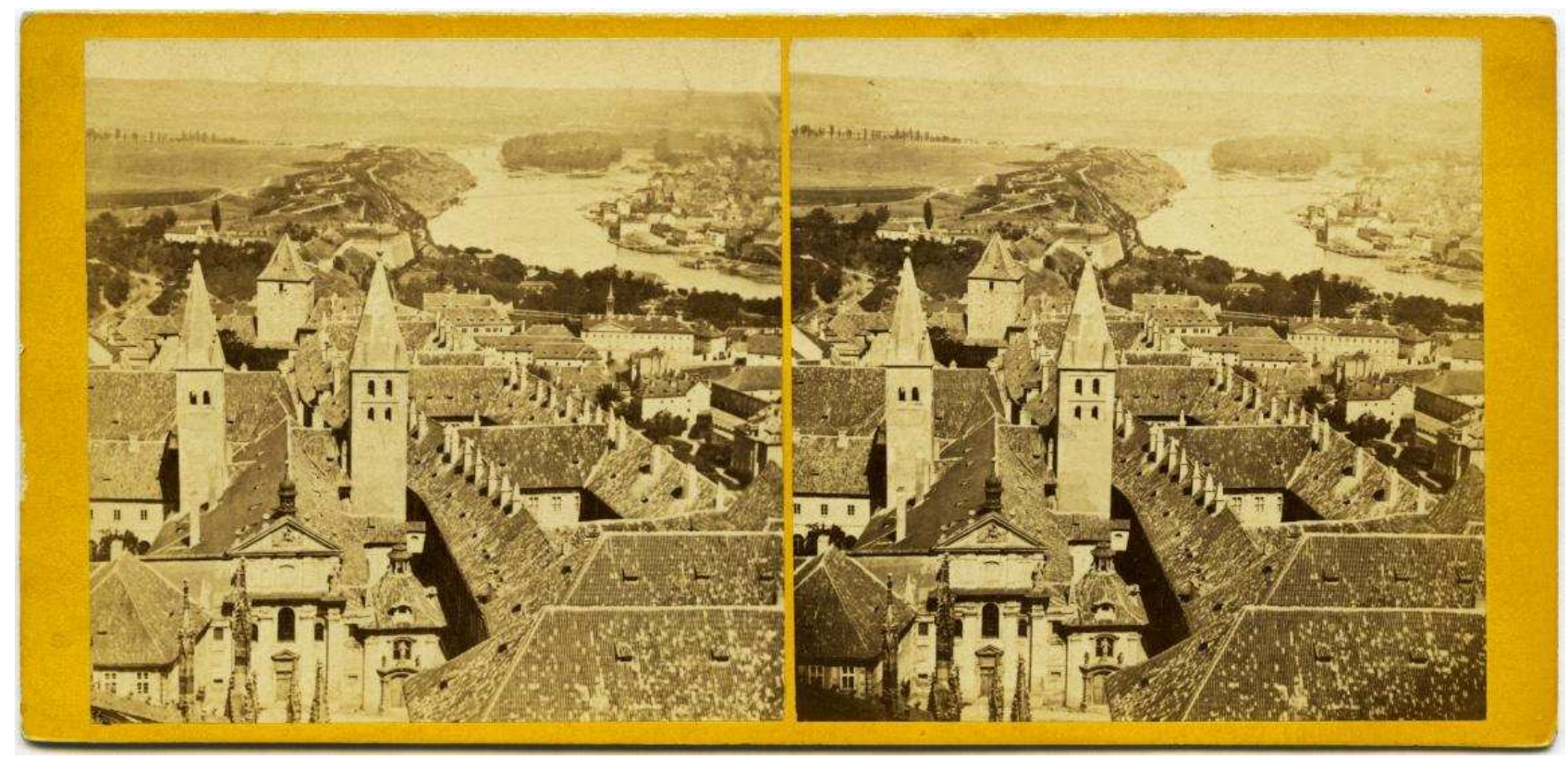

Figure 2: F. Fridrich (1867)

\section{MEASURING}

For the orientation purpose, it is necessary to identify as many as possible to present-day preserved points on the historical photograph. The most efficient method to fulfill the task is using present-day photogrammetric project, because it is possible efficiently measure large areas (areas presented on Figure 1 and 2) by photogrammetry, whereas using standard surveying techniques would be much more costly. The other reason for using photogrammetry is necessity of identification of the same points in the historical photograph and in the present-day reality. It is much easier to carry out the identification in the similar photograph to the historical one (similar inner and outer orientation) than in the different view from the terrestrial trigonometric measurement. It would be suitable to realize camera positions and orientation in configuration presented on the Figure 3. The only realizable possibility to accomplished suggested configuration is taking pictures from aerial model (further called Unmanned Aerial Vehicle - UAV). 


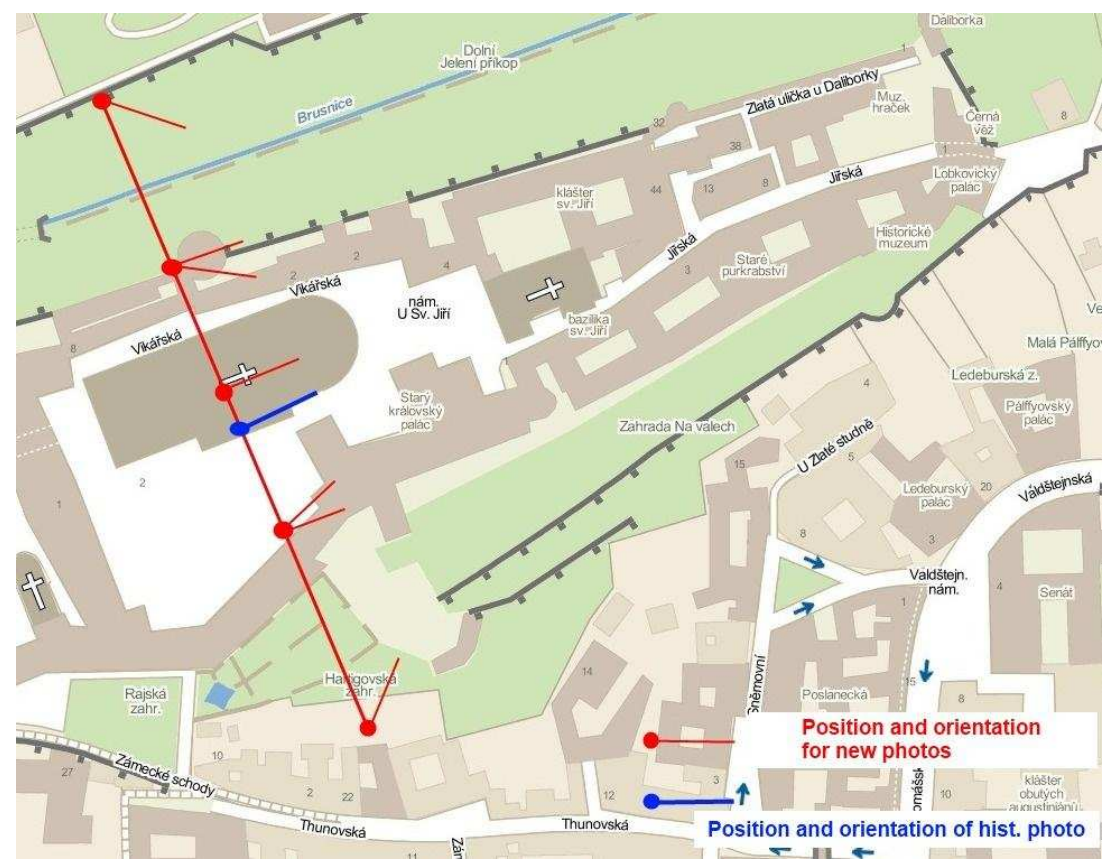

Figure 3: Suitable camera positions and orientation

\subsection{Present UAV photographs}

The model EasyUAV (see Figure 4) was used for taking photographs. EasyUAV is equipped with autonomous control of flight and with programmatic shooting of photographs - both, flight and shooting, can be planned before flight.

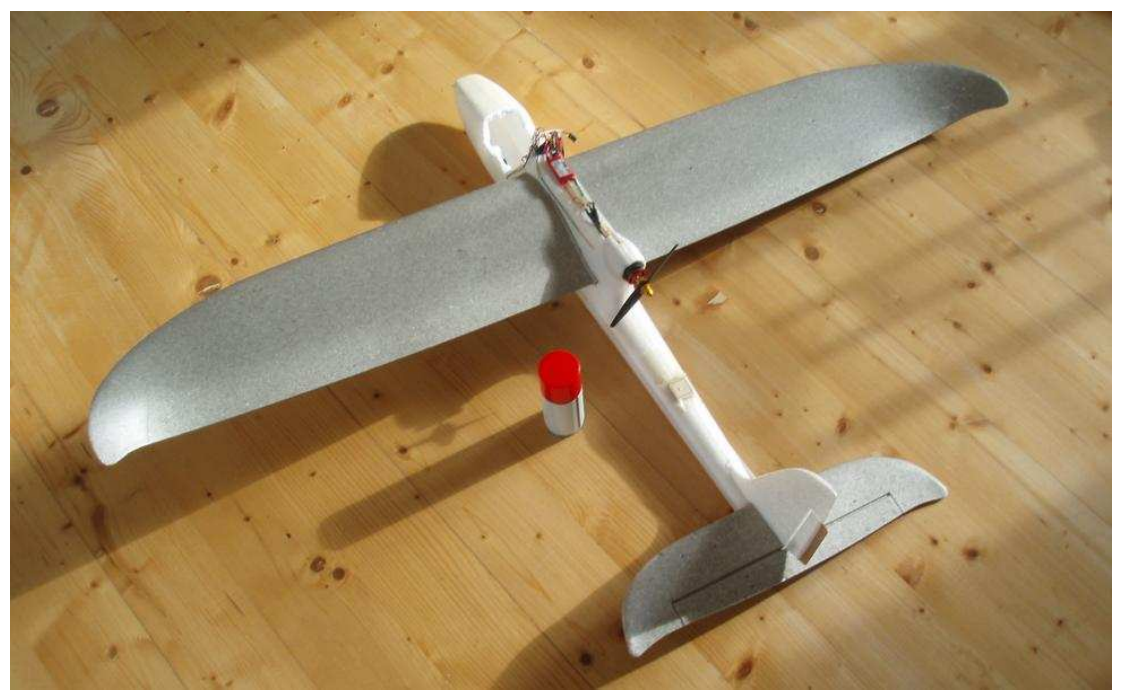

Figure 4: Picture of the EasyUAV model

The most important parameters of EasyUAV model are presented in the Table 1. 


\begin{tabular}{|l|l|}
\hline Wing span & $1.3 \mathrm{~m}$ \\
\hline Length & $1.3 \mathrm{~m}$ \\
\hline Weight (without camera and battery) & $700 \mathrm{~g}$ \\
\hline Maximal laden weight & $1150 \mathrm{~g}$ \\
\hline Usual load & $450 \mathrm{~g}$ \\
\hline Typical flight time & $15-75 \mathrm{minut}$ \\
\hline Speed typical / maximal & $40 / 90 \mathrm{~km} / \mathrm{h}$ \\
\hline Flight range radius & $5 \mathrm{~km}$ \\
\hline
\end{tabular}

Table 1: Basic parameters of the EasyUAV model

The special lightweight camera Sony NEX-5 was chosen for the model. It is a representative of a new camera category (in 2010), which combines size and weight of "compact camera" category and some important properties of reflex camera. It incorporates concretely larger size CCD chip of the APS-C standard $(23.4 \times 15.6 \mathrm{~mm}$ in the case) and interchangeable lenses. The fix focal length lens $16 \mathrm{~mm}$ was used in the project because of its lightweight and geometrical stability. Other important property of the camera is 14 Mpixels resolution and full manual control possibility. The flight trajectory and shooting position for the project was defined in Google Earth software and transformed to the EasyUAV control software in advance (see Figure 5 left).
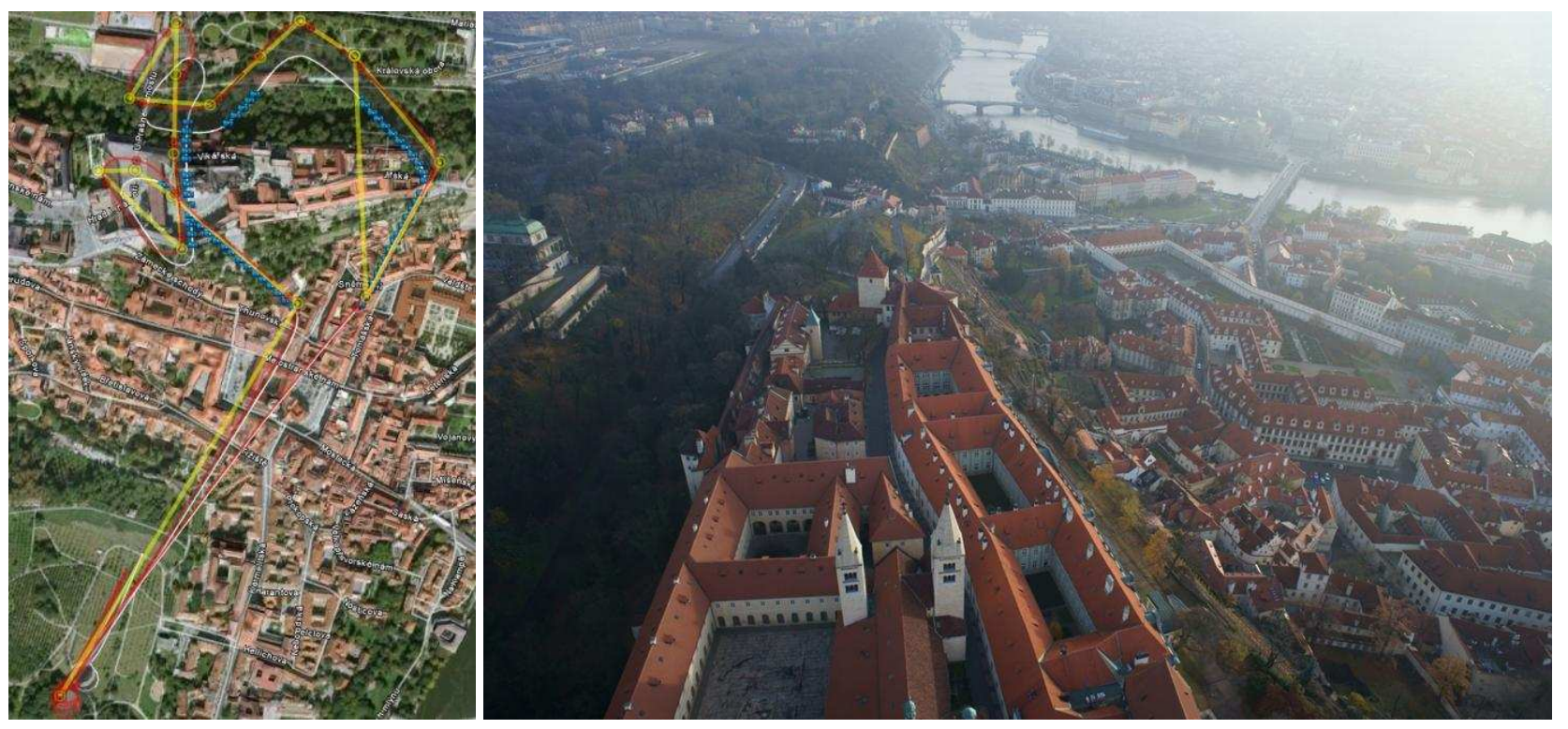

Figure 5: Flight trajectory and shooting position plan and an example of realized photography

95 photographs were acquired in total. The whole flight time (from takeoff to landing) took approximately ten minutes. One photograph with similar orientation as historical one is for illustration on the Figure 5. It is evident that for higher accuracy/resolution of photographs shorter shooting distances should be used. Flight trajectory was suggested with respect to safety aspect (flight deviation from planned trajectory) at least 20 meter above highest point in the Prague Castle area - south tower of St. Vitus Cathedral. The new flight was not realized for time reasons and more photographs that are accurate were acquired from terrestrial positions instead.

\subsection{Present terrestrial photographs}

Some additional photographs were also acquired from outer gallery of St. Vitus Cathedral and from terrestrial place in front of St. George Basilica to obtain higher accuracy of photogrammetric project. Calibrated digital reflex camera 
Canon EOS500D with fix focus lens $35 \mathrm{~mm}$ were used for the task. An example of terrestrial photograph is on the Figure 6.

\section{PROCESSING}

It is possible to use two approaches for processing. The situation is easier if we only need an evaluation of historical angle. In the case it is possible to use standard photogrammetric software e.g. PhotoModeler. However, if we also need reliable estimation of historical angle standard deviation, we have to use more complex approach which includes creation of own bundle adjustment (further is used the abbreviation BA) implementation with more possibilities that is available in standard software.

\subsection{Processing in the PhotoModeler software}

The first processing was realized in the PhotoModeler software (further named PM). Its results could be used for determination of historical angle and was used as approximate values for own BA implementation. The present-day photographs (11 from EasyUAV and 8 terrestrial) were chosen in the first stage. Transformation was used for setting of project orientation and size. Axis $\mathrm{Z}$ was put to the southwest edge of south tower, which is almost perfectly vertical (see [1]), and axis $\mathrm{X}$ is placed to the plane defined by points 42, 43 and 44, which represents west walls of towers, see Figure 6 . Thanks to the axis orientation only XZ coordinates determine the north-south angle and Y coordinate does not have to be used in further calculations.

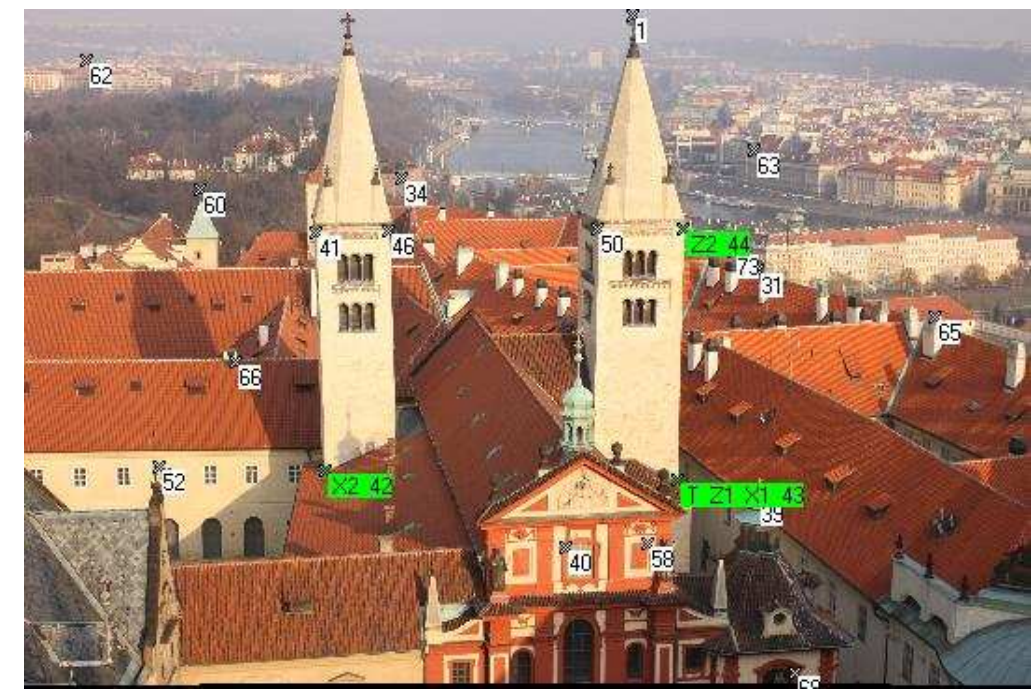

Figure 6: Transformation for setting of project orientation and size

The basic statistical information about the project in PM are: Standard deviation a posteriori $\sigma_{0}$ (total error in PM) 0.759 (a priory 1 pixel), 73 3D points, 3D point were marked on 5 photographs in average, there were 20 points marked on photograph in average. The historical photograph was joined to the project next. The experience with the historical photograph Eckert is described in the following text. Inverse camera (focal length, principal point and aspect ratio) was set for it. Image points were identified on the historical photograph besides towers area. 13 points were identified see Figure 7. It can be supposed that the chosen points were stable or nearly stable in its position between 1872 and presentday. $\sigma_{0}$ increased to 0.944 pixel after processing together with historical photograph. Standard deviation of the historical photograph was 2.52 pixels (maximal 5.8). The historical photograph has higher standard deviation, because it is uncalibrated image after range of transformations and because of its higher resolution 5978x4298. The next step was fitting of a surface through the west walls of towers in the present-day photographs and marking points on edges of the historical photograph. The only southwest edge of the south tower (further named $\mathrm{H} 1$ - in present-day is nearly perfectly vertical) and northwest edge of north tower (further named H2) were used because of its higher quality for identification. It is easy to compute mutual angle in north-south direction of both towers in 1872 from the points on $\mathrm{H} 1$ and $\mathrm{H} 2$ according to the equation (1) - point indexes used according to the Figure 7 and axes orientation according to the Figure 6. 


$$
\Delta \alpha=\arctan \left(\frac{\Delta \mathrm{x}_{102,103}}{\Delta \mathrm{z}_{102,103}}\right)-\arctan \left(\frac{\Delta \mathrm{x}_{96,97}}{\Delta \mathrm{z}_{96,97}}\right)
$$

The angles and its deviations are stated computed for the height 15 meters (seeable part of towers is $14-17$ meters) for the reason of transparency in the text. The historical mutual angle $\Delta \alpha$ recomputed for 15 meters is $0.302 \mathrm{~m}$ derived from the Eckert and 0.248 from the Fridrich. More complex task is estimation of the angle deviations, which is described further in the text.

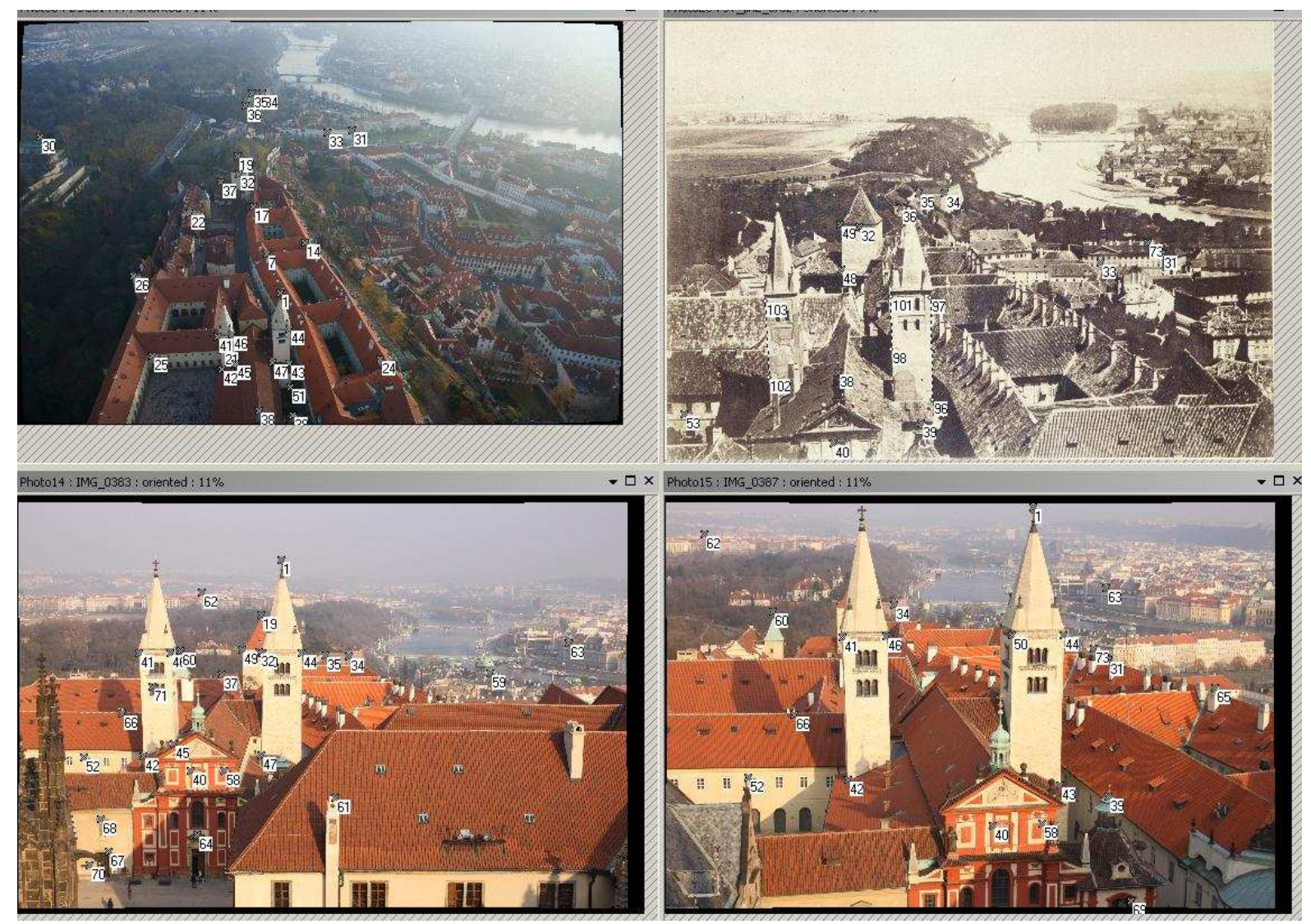

Figure 7: Choosing of identical points on historical and present-day photographs

The spin-off of the historical photograph orientation was determination of its position during photographing in 1872 see Figure 8. The meaningful position is also a control of gross errors in project orientation.
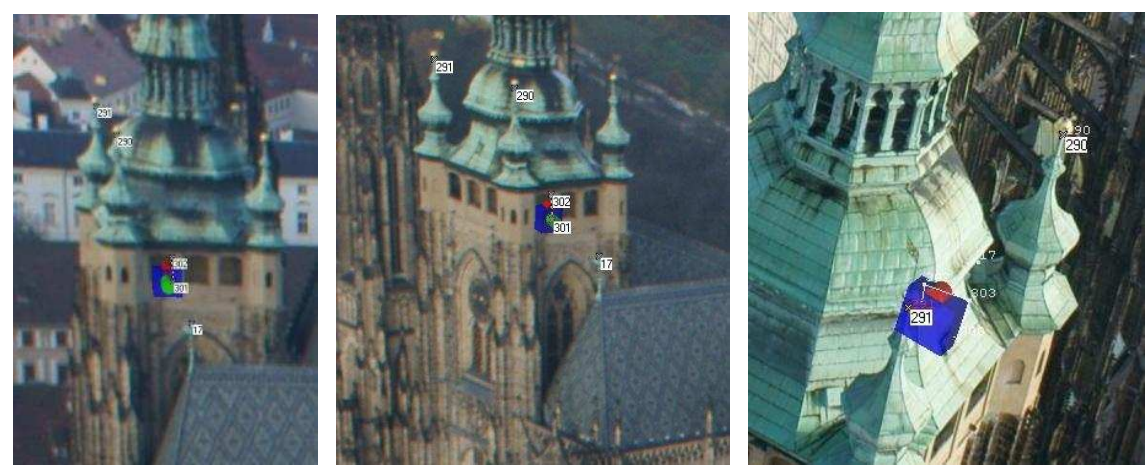

Figure 8: Position and orientation of historical photograph shown in present-day photographs 


\subsection{Methodology verification using standard surveying methods}

An independent verification of angle $\Delta \alpha$ derived from the present-day photogrammetry project is comparison of its value with the results from standard surveying techniques described in [1]. There is stated $\Delta \alpha$ angle $0.351 \mathrm{~m}$ for 15 meter in the literature [1]. This value is not tightly in correspondence with angle from photogrammetry, which is 0.254 $\mathrm{m}$. There exists an objective reason for the discrepancy. The angle was derived only from top 7 meters below the roof in [1] and the edges of towers are not perfectly linear. The special targets were placed on the towers for the measurement see Figure 9 left. That's why there were added points 72 and 73 in photogrammetric project too - see Figure 9 . When the angle between new points and the top of the towers was computed, very good correspondence was achieved. The angle value from photogrammetry is $0.341 \mathrm{~m}$.
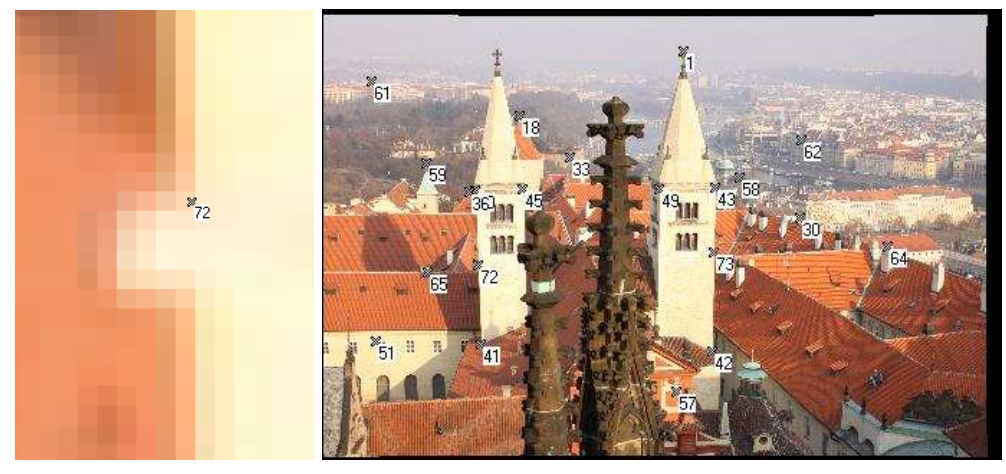

Figure 9: Points 72 and 73 near standard surveying points for inclination determination

\subsection{Estimation of angle standard deviation}

The most complex problem of the project is estimation of determined angle standard deviations. There exist three essential reasons why the PM software and similar ones cannot be used for the purpose. At first, it is not possible to get full covariant matrix of adjusted values from it. Points related to individual photographs are very closely correlated and that's why relations between those points have significantly lower standard deviation than is their total standard deviation. The second reason is that there is not any possibility to get standard deviation of points computed from intersection of surface and optical direction from the camera in the PM software, what is the case of tower points in historical photographs. These standard deviations can be generally computed and depend on the results of adjustment. The last reason is that it is not possible to use different accuracy (weight) for individual images in the PM project. It is evident that historical photographs have lower accuracy than present-day ones, because it is uncalibrated and influenced by range of transformations. The PM software shows standard deviations for adjusted parameters (camera orientation and position and 3D points). These standard deviations are "absolute" related to the project coordinate system, so they tightly depend on project coordinate system definition. This problem is called the "Datum" (or "Gauge") problem and many materials are dedicated to it e.g. [2, 3]. For example, if the most general method "Free network method" is used in our project (in PM - processing without constraints and control points) and the law of error propagation [4] is applied on the equation (1), the standard deviation of angle $\sigma_{\Delta \alpha}$ is $0.618 \mathrm{~m}$. If the full covariant matrix is used in the same example, the standard deviation of angle $\sigma_{\Delta \alpha}$ is only $0.012 \mathrm{~m}$. If the datum is defined by 7 coordinate conditions - two points on $\mathrm{H} 1$ and $\mathrm{Y}$ coordinate of point on $\mathrm{H} 2$ are chosen to be fixed (it represents ideally chosen datum fixation for minimal standard deviations), the standard deviation of angle $\sigma_{\Delta \alpha}$ is $0.024 \mathrm{~m}$. Stated deviations are related to the present-day angle and project. If full covariant matrix is used in the law of error propagation, the results of adjusted parameters functions are invariant to the datum choice. It is necessary to use full covariant matrix to get reliable estimation of $\sigma_{\Delta \alpha}$. The second aspect is determination of historical angle standard deviation. As was said before, there is not possibility to compute standard deviation of points computed from intersection of surface and optical direction from the camera in the PM software, but it is possible in general. A plane can approximate the west tower walls. A small movement of the plane in the west-east direction cannot significantly influence angle $\Delta \alpha$ so, it is not necessary to assign any standard deviation to the plane parameters and they can be treated as constants (standard deviation can be assign to them if it is necessary). It is possible to define simple constrain $y_{i}=0$ for points $i=96,97,102,103$ (see Figure 7 upright) because of suitably chosen coordinate system see Figure 6. Bundle adjustment (further named BA) with the constrains give a covariant matrix including points $93, \ldots, 103$ and can be used for $\sigma_{\Delta \alpha}$ computation. The last problem with processing in PM is impossibility of using different weight (standard deviation) for individual photographs. There is set a default standard deviation one pixel for manual marked points in an image. It is reasonable choice for calibrated photographs. A historical photograph is not calibrated and it is influenced by range of transformations, that's why the default value of standard deviation doesn't seam appropriate for it. Estimation of its true value is very complicated, but 
the photograph standard deviation from BA can be used. The present-day photographs have $\sigma_{0}$ in range $0.30-1.26$ pixel with mean 0.759 and $\sigma_{0}$ of Eckert is 2.52 and of Fridrich 1.86 in PM. 3D points were computed from five present-day photographs in average, that's why $\sigma_{0}$ a posteriori of historical photograph can be used as a reasonable estimation of its accuracy. The only possibility how to use it in PM is reducing the resolution of historical photograph, but it is not useful, because point marking would be less accurate then. Covariant matrix of adjusted parameters in BA has an equation (3).

$$
\begin{aligned}
& \mathbf{P}_{\text {in }}=\sigma_{0 \text { apr }}^{2} \cdot \mathbf{S}_{\text {in }}^{-1} \\
& \mathbf{S}=\sigma_{0}^{2} \cdot \mathbf{N}^{-1}=\frac{\mathbf{r}^{\mathrm{T}} \mathbf{P}_{\text {in }} \mathbf{r}}{\mathrm{n}} \cdot \mathbf{J}^{\mathrm{T}} \mathbf{P}_{\text {in }} \mathbf{J}^{-1}=\frac{\mathbf{r}^{\mathrm{T}} \mathbf{P}_{\text {in }} \mathbf{r}}{\mathrm{n}} \cdot \mathbf{J}^{-1} \mathbf{P}_{\text {in }}^{-1}\left(\mathbf{J}^{\mathrm{T}}\right)^{-1}=\frac{\mathbf{r}^{\mathrm{T}} \mathbf{S}_{\text {in }}^{-1} \mathbf{r}}{\mathrm{n}} \cdot \mathbf{J}^{-1} \mathbf{S}_{\text {in }}\left(\mathbf{J}^{\mathrm{T}}\right)^{-1}
\end{aligned}
$$

$\mathrm{n}$ is a number of redundant measurement, $\mathbf{P}_{\mathbf{i n}}$ is weight matrix and other parameters are described later in the text. From the equation (3) is clear that the covariant matrix $\mathbf{S}$ is defined by Jacobian matrix $\mathbf{J}$ (spatial configuration of the project), covariant matrix of input values $\mathbf{S}_{\text {in }}$ (marking of points) and by a posteriory standard deviation $\sigma_{0}$. $\mathbf{S}$ is not influenced by actual residuals, besides $\sigma_{0}$ (in the case of using a priory $\sigma_{0}$, it is not influenced by residual at all). The only changeable parameter influencing $\mathbf{S}$ matrix is $\mathbf{S}_{\text {in }}$ matrix and if this matrix is not chosen right, the resulting accuracy characteristics will not be reliable. For illustration, in the case of using wrong (default 1 pixel) standard deviation for historical photograph we get $\sigma_{\Delta \alpha} 0.044 \mathrm{~m}$ for Eckert ( 0.038 for Fridrich). In the case of using reasonable value 2.5 pixel for Eckert ( 2 for Fridrich) we get $\sigma_{\Delta \alpha} 0.061 \mathrm{~m}$ for Eckert (0.071 for Fridrich).

\section{RESULTS}

The main result of the project is determination of historical angle between St. George Basilica towers and its standard deviation. Angle $\Delta \alpha$ recomputed for 15 meters is $0.302 \mathrm{~m}$ derived from the Eckert and 0.248 from the Fridrich. Its standard deviations $\sigma_{\Delta \alpha}$ is $0.061 \mathrm{~m}$ for Eckert and $0.071 \mathrm{~m}$ for Fridrich. The present-day angle is $0.254 \mathrm{~m}$ with $\sigma_{\Delta \alpha} 0.012$ $\mathrm{m}$. It is clear that angle change cannot be proofed from the presented results. Change would be provable if its value is higher than $0.061 \times 2=0.122 \mathrm{~m}$. Computed change is only $0.048 \mathrm{~m}$ (Eckert).

\section{SUMMARY}

Determination of historical angle in the north-south direction between St. George Basilica towers from contemporary historical photographs is presented in the paper. At first, the suitable historical photographs had to be found in the archives. Next, taking of present-day photographs from proper positions had to be realized. The photographs were taken using small UAV model and from neighbouring building. The determination of historical angle was pretty straightforward. The standard project in PhotoModeler software was sufficient for the task. The historical photograph was included in the project with inverse camera setting. The most demanding part was determination of angle standard deviation. Standard photogrammetric software like PhotoModeler can't be used for the purpose for several reasons. It is not possible to get full covariant matrix from them, they don't give accuracy characteristic for intersection of surface and optical direction from the camera and it is not possible to use different weight for individual photograph in it. That is why own bundle adjustment implementation was created, which enables reliable estimation of the angle standard deviation.

\section{ACKNOWLEDGEMENTS}

This research has been supported by MSM 6840770005.

\section{REFERENCES}

[1] Procházka, J., Záleský, J., Jiřikovský, T., Salák, J.: Long-term Stability Monitoring in the Prague Castle Area, Acta Geodynamica et Geomaterialia. Vol. 7, no. 4, p. 411-429, 2010.

[2] McGlone, J. Ch. (Editor), Mikhail, E. M. (Editor), Bethel, J. S. (Editor), Mullen, R. (Contributor): Manual of Photogrammetry - Fifth Edition, ASPRS, 2004, ISBN 1570830711.

[3] Triggs, B., McLauchlan, P., Hartley, R., Fitzgibbon, A.: Bundle Adjustment - A Modern Synthesis, Vision algorithms theory and practice, Springer, vol. 34099, p.: 298-372, 2000, ISBN: 3540679731. Available online:

<http://www.springerlink.com/index/PLVCRQ5BX753A2TN.pdf>

[4] Koch, K-R.: Parameter Estimation and Hypothesis Testing in Linear Models, Springer, Germany, 1999. 